\title{
THE IMPACT OF CAMSHAFT CONTROL ON COMBUSTION PROCESSES IN A COMPRESSION IGNITION VCR ENGINE
}

\author{
Jerzy Merkisz $^{1 *}$, Maciej Bajerlein ${ }^{2}$, Paweł Daszkiewicz ${ }^{3}$, Patryk Urbański ${ }^{4}$ \\ ${ }^{1}$ Poznan University of Technology, Faculty of Civil and Transport Engineering, Piotrowo 3, 60-965 Poznań, Polska, \\ email: jerzy.merkisz@put.poznan.pl \\ ${ }^{2}$ Poznan University of Technology, Faculty of Civil and Transport Engineering, Piotrowo 3, 60-965 Poznań, Polska, \\ email:maciej.bajerlein@put.poznan.pl \\ ${ }^{3}$ ŁUKASIEWICZ-IPS „TABOR”, Warszawska 181, 61-055 Poznań, email: p.daszkiewicz@tabor.com.pl \\ “ŁUKASIEWICZ-IPS „TABOR”, Warszawska 181, 61-055 Poznań, email: patryk.urbanski@tabor.com.pl \\ ${ }^{*}$ Corresponding author
}

Reviewed positively: 15.10 .2019

Information about quoting an article:

Merkisz J., Bajerlein M., Daszkiewicz P., Urbański P. (2020). The impact of camshaft control on combustion processes in a compression ignition VCR engine. Journal of civil engineering and transport. 2(1), 9-18.

ISSN 2658-1698, e-ISSN 2658-2120, DOI: 10.24136/tren.2020.001

\begin{abstract}
The article contains an analysis of thermodynamic indicators of the $\mathrm{Cl}$ engine ${ }^{1}$ with direct fuel injection. The tested unit was an engine with an unconventional crank-piston configuration, in which at a constant compression ratio, different engine crankshaft control variants were compared In this article the time ranges in which the piston was located in the TDC ${ }^{2}$ were analyzed. Additionally, tests were carried out on a conventional unit for comparative purposes. For the purposes of the work, a piston displacement characteristic was generated in dynamic analysis in SolidWorks Motion $^{3}$. Then, this characteristic was used in the simulations of the combustion process in the AVL Fire program, where the most important thermodynamic indicators of the engine cycle were analyzed.
\end{abstract}

Key words - VCR ${ }^{4}$ engine, indicating, AVL Fire

JEL Classification - Q42

\section{INTRODUCTION}

In the piston engine, one of the basic construction parameters determining, for example, the general engine efficiency, is the geometric compression ratio $\varepsilon$, which is expressed as a reciprocal value of the ratio of the minimum volume of the combustion chamber $V_{\min }$, with the piston position at the TDC, to the maximum cylinder volume $V_{\max }$, i.e. when the piston is at the $\mathrm{BDC}^{5}[1-3]$. The operating conditions of the internal combustion engine are variable, therefore the constant, structurally determined value of the geometric compression ratio does not ensure optimal operating conditions, and as a result the efficiency of the entire drive system decreases. Currently, the most efficient units reach a maximum of about $40 \%$ efficiency while maintaining ideal operating conditions, meaning they are losing more than half of the fuel energy.
By increasing the geometric compression ratio, the power and efficiency of the engine can be increased, at the cost of increasing the risk of engine knock, which poses a risk of engine damage [4-7]. The solution may be to use a variable geometric compression ratio that allows for a dynamic change of $\varepsilon$ during engine operation. VCR allows adjusting this parameter depending on the operating conditions, as well as to allow using alternative fuels and low-temperature combustion processes [8-11]. In addition, in some solutions of VCR engines, it is possible to control the piston's kinetics in such a way as to accelerate or slow down specific piston strokes or, for example, stop the piston in the TDC for a certain short period of time.

\section{Test Object}

Szymkowiak's engine is a reciprocating piston engine with a variable compression ratio using a crank and piston mechanism. The inventor of the 
engine is MSc. Mirosław Szymkowiak. The engine has the ability to operate on multiple fuels, which differ significantly in terms of parameters (it is designed with the idea to be able to run on gasoline with different octane number, diesel oil, natural gas or biofuels). The unit is an eight-cylinder engine with cylinders placed in a two-row system (4 cylinders per row). The engine has the dimensions of a $60 \mathrm{~cm}$ side cube. It also has the ability to smoothly adjust the compression ratio in operation from 9:1 to $14.5: 1$, by rotating the camshaft. The movement of the piston is transferred to the swingarm using a connecting rod attached to the swingarm with a bolt. Then the swingarm movement is converted into a rotational movement, thanks to the connection of the crankshaft to the swingarm through the connecting rod. The swingarm is also pivoted on the camshaft. The engine height has been reduced by placing the crankshaft between the cylinder rows (Fig. 1)

The Szymkowiak's engine and the conventional engine were created in the Solidworks program to compare the combustion processes between the two solutions. The engine with variable compression has been designed in the 3D program in a way that accurately reproduces all dimensions and geometrical relationships from the real engine. Geometric dimensions in the case of a conventional engine have been selected to be the same, i.e. the piston diameter, stroke, crankshaft shape. Both models have been simplified while maintaining all the important dimensions (Fig. 2) to shorten the simulation time.

In order to compare the combustion processes depending on the duration of the piston remaining in the TDC, it was necessary to use the piston displacement for each variant (Fig. 3). The piston motion test was carried out on previously created 3D models. In Solidworks, the Motion Study tab generated the piston motion for each of the considered options. The obtained data should have been saved in a specially prepared txt file.

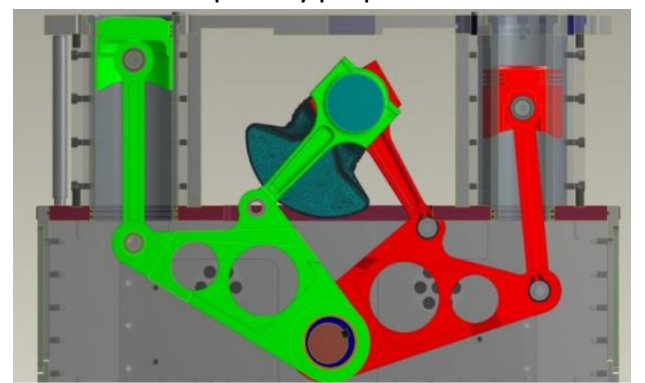

Fig. 1. Cross-section of Szymkowiak's engine with visible innovative crank-piston arrangement

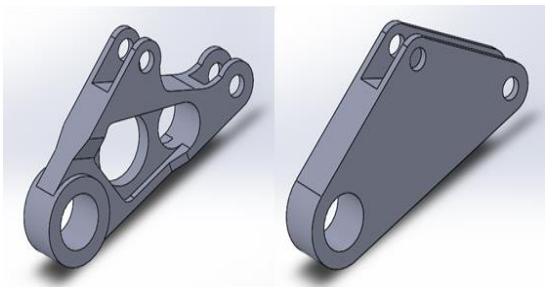

Fig. 2. Simplified geometry of the swingarm in Szymkowiak's engine

\section{COMBUStION PROCESS ANALYSIS}

The combustion process simulation was carried out in the AVL Fire software. One of the segments

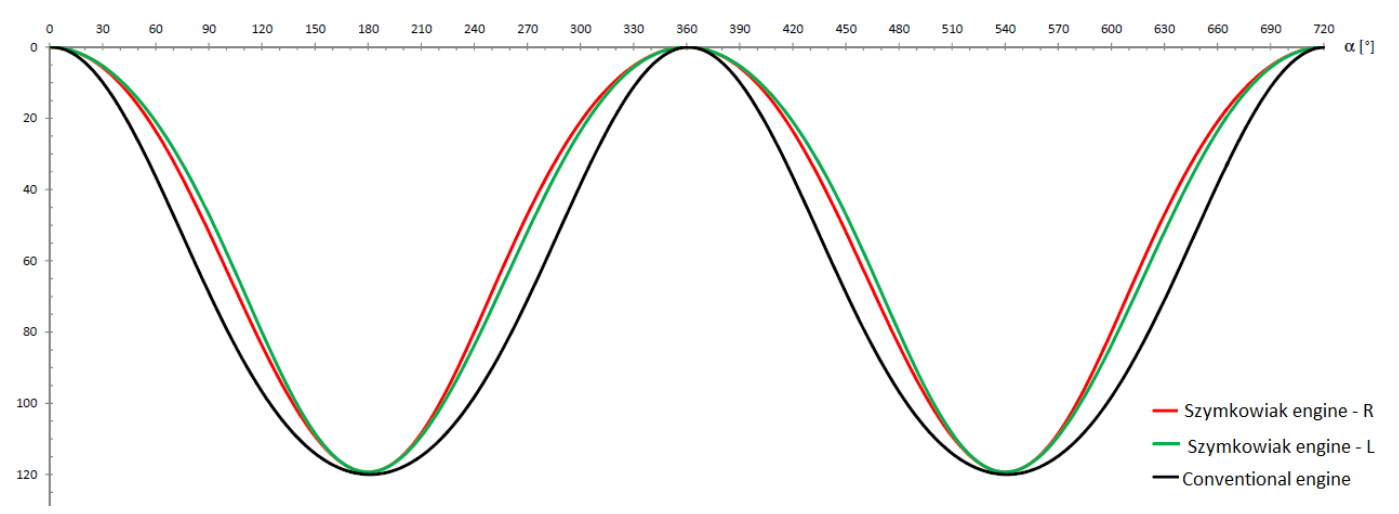

Fig. 3. Example of the piston motion curves in conventional and Szymkowiak engines. L - Left cylinder, R-Right cylinder 
of the program is the ESE Diesel ${ }^{6}$ module specially designed to create simulations of compressionignition engine processes. In this version of the program, simulations have been created for the compression-ignition crank and piston engines. At a later stage, they were used to analyze the phenomena occurring in the combustion chamber. For the needs of the simulation, the combustion chamber was prepared (Fig. 4) based on the available parameters and the engine data.

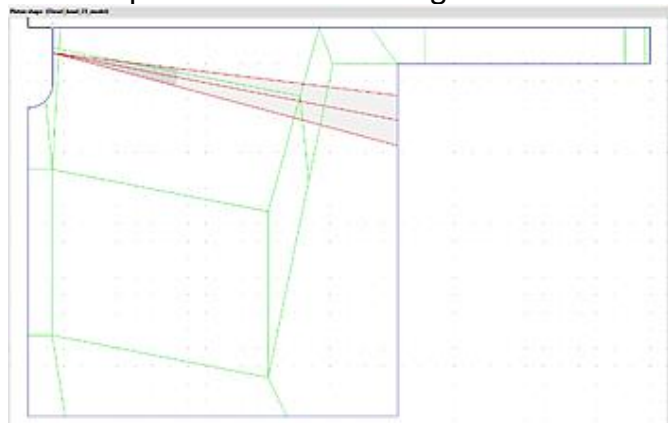

Fig. 4. The shape of the combustion chamber generated in the AVL program

The cylinder-shaped combustion chamber with the piston diameter and the height corresponding to the analyzed cases was imported from the Diesel Bowl module. Important assumptions made during the creation of the combustion chamber were: no turbulence, no dose exchange and a flat piston crown. The tested engine was supplied by direct injection of diesel into the cylinder. A 4-hole injector was used, with the atomizer tip located $4.5 \mathrm{~mm}$ from the bottom of the piston. Spray angle was $8^{\circ}$.

The next important stage in modelling the combustion chamber is the parametric grid (Fig. 5).

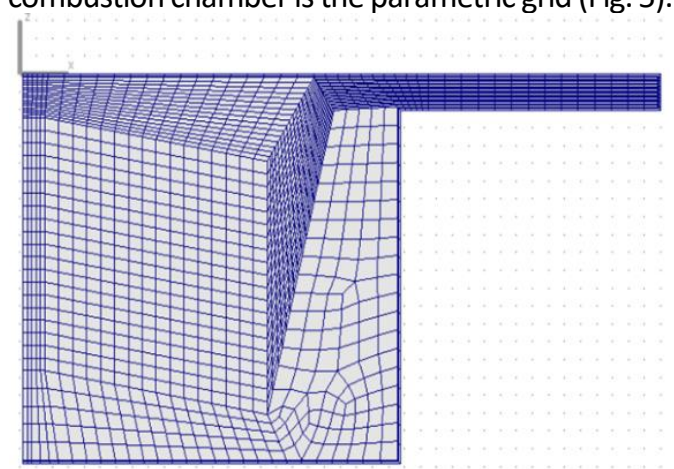

Fig. 5. 3D mesh of the combustion chamber segment in the AVL Fire Workflow Manager
The blocks were generated based on Topology 0 . The mesh creation procedure enables the analysis of the combustion process, which is why its highest accuracy was required especially within the fuel stream. Dimensions of combustion chambers were designed for the piston being in TDC. However, as the piston moves with the crankshaft rotation, the mesh stretches, increasing its density. Due to the high computing power required, the program divided the combustion chamber into parts of identical sizes. The number of elements was equal to the injector holes.

An important step is insert into the AVL Fire program of the previously generated piston displacement created in the dynamic analysis. The tested motion range was determined to be $540^{\circ}$ to $800^{\circ}$ crankshaft angle, which corresponds to the compression stroke (range $540^{\circ}-720^{\circ}$ ) and the most important part of the combustion stroke (in the range from $720^{\circ}$ to $800^{\circ} \mathrm{CA}$ ). The rotational speed of the crankshaft was set at 2000 rpm (Fig. 6).

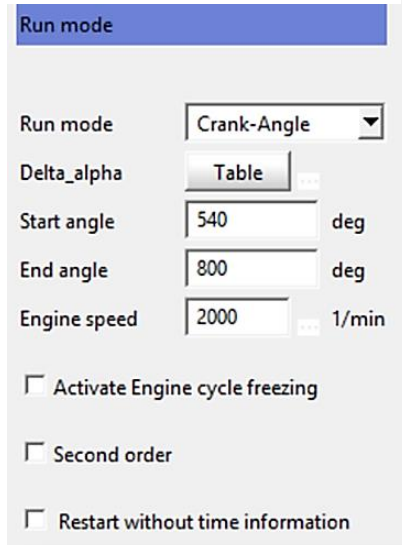

Fig. 6. Window for setting the angular range of the simulation and rotational speed

In order to increase the calculation accuracy more calculation steps were added in the most important simulation parts, i.e. the end of the compression and the initial phase of the combustion stroke (Fig. 7).

\begin{tabular}{|c|c|c|c|}
\hline & upto & crank-angle & Delta_alpha \\
\hline & & deg & deg \\
\hline 1 & upto & 690 & 1 \\
\hline 2 & upto & 740 & 0.25 \\
\hline 3 & upto & 750 & 0.5 \\
\hline 4 & upto & 780 & 1 \\
\hline 5 & upto & 800 & 1 \\
\hline
\end{tabular}

Fig. 7. Increase in calculation steps for the simulation in relation to the $\mathrm{CA}^{7}$ 
The impact of camshaft control on combustion processes in a compression ignition VCR engine

\begin{tabular}{|c|c|c|}
\hline Parameter & Value & Unit \\
\hline \multicolumn{3}{|c|}{ Fresh air injected } \\
\hline Pressure & 97000 & $\mathrm{~Pa}$ \\
\hline Air density & {$[-]$} & $\mathrm{kg} / \mathrm{m}^{3}$ \\
\hline Temperature & 340 & $\mathrm{~K}$ \\
\hline $\begin{array}{l}\text { Turbulent kinetic } \\
\text { energy }\end{array}$ & 11 & $\mathrm{~m}^{2} / \mathrm{s}^{2}$ \\
\hline Turbulent scale length & 0.003 & $\mathrm{~m}$ \\
\hline Initialization & Swirl/Tumble & {$[-]$} \\
\hline Turbulence velocity & 3000 & rpm \\
\hline \multirow{3}{*}{$\begin{array}{l}\text { Direction of the axis of } \\
\text { rotation }\end{array}$} & $x=0$ & \multirow{3}{*}[-]{} \\
\hline & $Y=0$ & \\
\hline & $Z=1$ & \\
\hline \multicolumn{3}{|c|}{ Exhaust recirculation } \\
\hline Fuel type & Diesel & {$[-]$} \\
\hline EGR mass fraction & 0.12 & {$[-]$} \\
\hline EGR composition & 0.478 & {$[-]$} \\
\hline Laminar flame velocity & Default & {$[-]$} \\
\hline
\end{tabular}

Simulations of the combustion process were made at an identical compression ratio of 14.3. For each of the 4 simulated cases, the geometrical dimensions of the combustion chambers were determined in such a way that the compression ratio was always the same.

Although in a real engine the compression ratio is variable for a different camshaft position, the change in the geometrical dimensions of the combustion chamber (change in height) is used for objective comparison of combustion processes for the different variants. The precise selection of engine parameters and operating conditions is important for performing the simulation. In order to obtain the most reliable results, the same simulation parameters were set for all variants (Table 1). and the injected fuel dose was $2.5 \mathrm{mg}$. For simulation purposes, direct fuel injection was assumed at $10^{\circ}$ before TDC, which lasts $0.39 \mathrm{~ms}$. These values were adopted due to compressionignition occurring at the TDC. The combustion model selected for the simulation is the ECFM- $3 Z^{8}$.

\section{Simulation RESULTS}

4 simulations of processes taking place in the cylinder were performed in the AVL program. One simulation concerned the combustion process in a conventional engine, the other 3 were simulated for a swingarm engine with an accelerated compression stroke (piston in TDC before $720^{\circ}$ ) for

different time durations of the piston remaining in this position: $712-724^{\circ}, 711-722^{\circ}, 710-730^{\circ} \mathrm{CA}$. All the obtained simulation results were compared to each other and then analyzed. The results for the conventional engine design were used as reference for the simulation results of the swingarm motor. For an objective comparison of solutions, the same boundary conditions were maintained throughout. The only changed parameter is the combustion chamber geometry, which has been adapted for each case in such a way that the compression ratio in each simulation remains the same at 14.3. The injected fuel dose for each case has been set to a constant value as well. The mean cylinder pressure, temperature and heat release rate were also taken into account.

\section{Mean Pressure Distribution}

The first simulation was carried out for the classic piston motion occurring in a conventional crank-piston system. The piston is in TDC when the crankshaft angle of $720^{\circ}$ is reached. The compression and combustion strokes last the same amount of time, so the piston motion is symmetrical between them. Compression ratio is identical to all cases, and is equal to 14.3. During the simulation, the maximum pressure which occurred in the combustion chamber was 63.1 bar and it was observed at $726.5^{\circ} \mathrm{CA}$. The combustion process of chemical reaction began at $721.5^{\circ} \mathrm{CA}$. The range of crankshaft angles for which the simulations were carried out was $540^{\circ}-800^{\circ}$. This value is sufficient to fully visualize the thermodynamic conditions occurring in the combustion chamber during the combustion stroke. The figure shows a characteristic point of pressure increase after the top dead center point is reached by the piston which indicates the validity of the simulation. The resulting curve for a conventional engine cause for this is a reference value for the remaining simulations. Its distribution can be found in Figure 8a.

The second simulation testing (Fig. 8b) was made using the asymmetric piston displacement, thus allowing it to remain at the TDC position for the whole range from 712 to $724^{\circ} \mathrm{CA}$. In the case of this simulation, the pressure curve is quite uniform. The graph clearly shows the moment at which the piston reached TDC. The pressure at $712^{\circ}$ CA is fixed at around 48 bar for a period of $4^{\circ} \mathrm{CA}$. The pressure increase is stopped by the injection of fuel which, through evaporation, temporarily impacts the pressure level in the chamber. After a short time the mixture spreads uniformly, and 
there is a rapid increase in pressure, which is caused by the ignition of the fuel-air mixture. The maximum value reached is 60.6 bar for the final phase of the piston remaining at the TDC, i.e. around $724^{\circ} \mathrm{CA}$. The effect of the maximum pressure in this stage is the sharper change in the parameter curve when the piston movement resumes. The pressure curve during the combustion stroke is also characterized by the lack of a clear smoothing of the pressure in the chamber in the range of maximum values, as was the case for fuel injection. The maximum obtained pressure was about $4 \%$ lower than for conventional engine. The probable cause for these is the higher piston acceleration compared to a conventional engine. The reason is the significant reduction of the compression time, which leads to large turbulence, and the increase in pressure is rapid and nonuniform. The maximum value was obtained when exceeding $719^{\circ} \mathrm{CA}$ and equaled $60.7 \mathrm{bar}$. This is the same level as obtained in the second simulation. There is a clear moment when reaching the peak pressure value in the combustion chamber and its stabilization within about $5^{\circ} \mathrm{CA}$. At the start of the
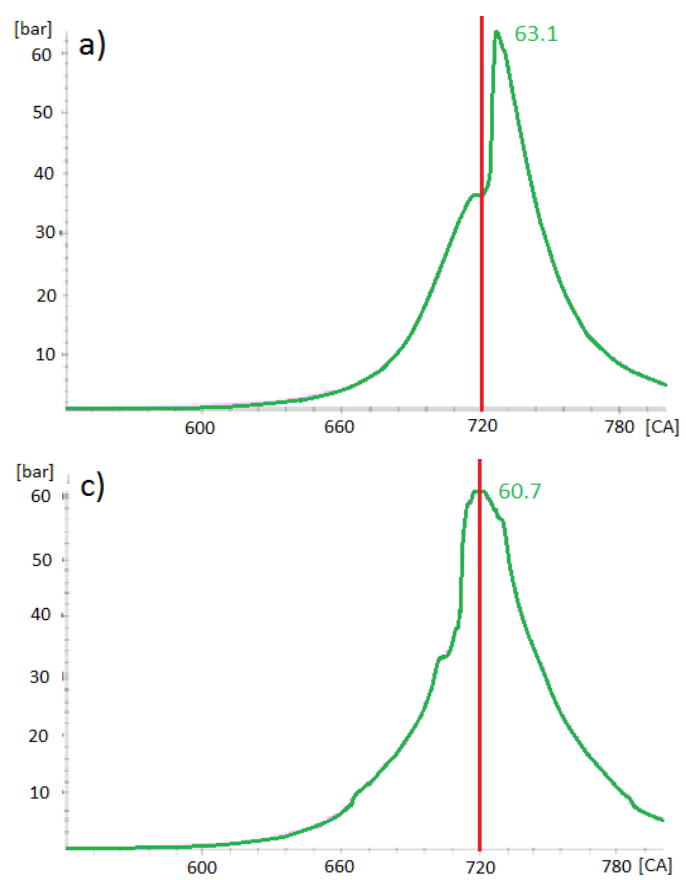

combustion stroke the cylinder pressure drops immediately in the span of several degrees past the TDC. Initially, the curve is characterized by a relatively mild shape, but then the pressure drop happens much faster.

The third analysis was carried out for the piston displacement calculation where the piston remained in the TDC in the crankshaft angle range of $711^{\circ}$ to $722^{\circ} \mathrm{CA}$ (Fig. 8c). The modeled displacement shows asymmetry with respect to the conventional axis at $720^{\circ} \mathrm{CA}$, which results in a significant piston acceleration in the compression stroke. The pressure curve for this stroke is characterized by significant deflections and irregularities. Maximum pressure in this simulation was equal to 60.7 bar around $719^{\circ} \mathrm{CA}$.

The last simulation performed considered the case when the piston displacement was symmetrical with respect to the $720^{\circ}$ CA point, similar to a conventional engine. The angle range covering the TDC starts at $710^{\circ} \mathrm{CA}$, and its end is at the moment when it exceeds $730^{\circ} \mathrm{CA}$ (Fig. 8d). This range also limits the duration of the piston movement being stopped and kept in the TDC,
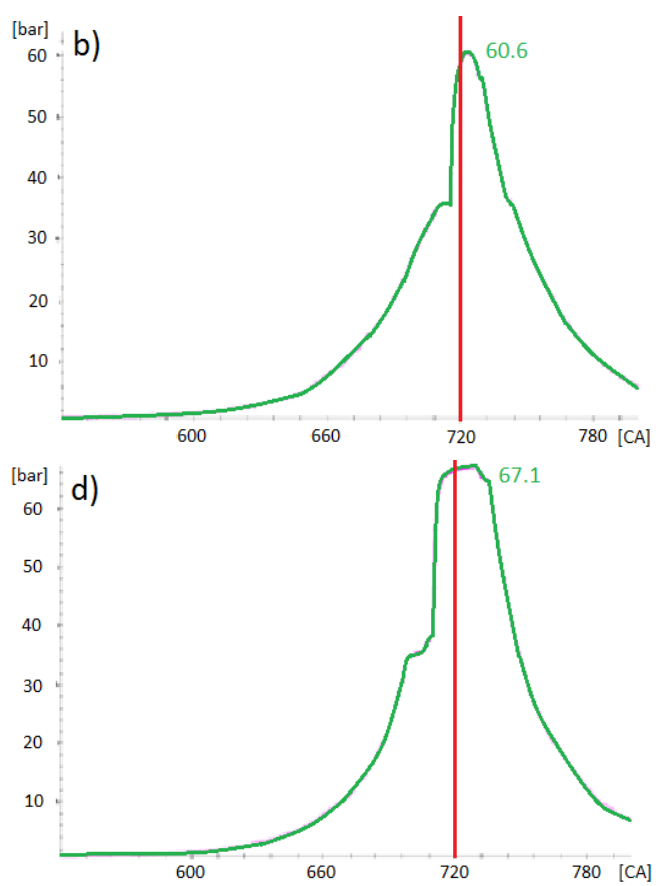

Fig. 8. Distributions of cylinder pressure in engines: a) conventional, b) swingarm for TDC at $712-724^{\circ} \mathrm{CA}$, c) swingarm for TDC at $711-722^{\circ} \mathrm{CA}, \mathrm{d}$ ) swingarm for TDC at $710-730^{\circ} \mathrm{CA}$. The blue line marks the $720^{\circ}$ point on the crankshaft 
which is possible for this engine design. A constant pressure range clearly emerged near the peak values, which is by far the longest of all the conducted simulations. The maximum recorded pressure was 67.1 bar. This means that it is the highest pressure value of all the results presented here and even exceeds the value obtained for a conventional engine by $6 \%$. The peak value was reached at $729^{\circ} \mathrm{CA}$, however, the limit of 60 bar was reached at $711.75^{\circ} \mathrm{CA}$, i.e. $1.75^{\circ}$ after the piston has reached its TDC. The piston, starting the combustion stroke, causes a rapid pressure drop, which later stabilizes.

\section{TEMPERATURE DISTRIBUTION}

The first simulation was made for a conventional internal combustion engine, where the piston movement shows symmetry with respect to $720^{\circ}$ $\mathrm{CA}$. The moment of ignition at the symmetry point is clearly visible as the temperature rises rapidly. This parameter stops to increase after reaching its maximum value at $1632.2 \mathrm{~K}$. The peak level was at $8.5^{\circ} \mathrm{CA}$ after TDC. This was shown in Figure 9a. A drastic temperature increase can be observed behind the TDC. This is closely related to the combustion chamber pressure and the heat
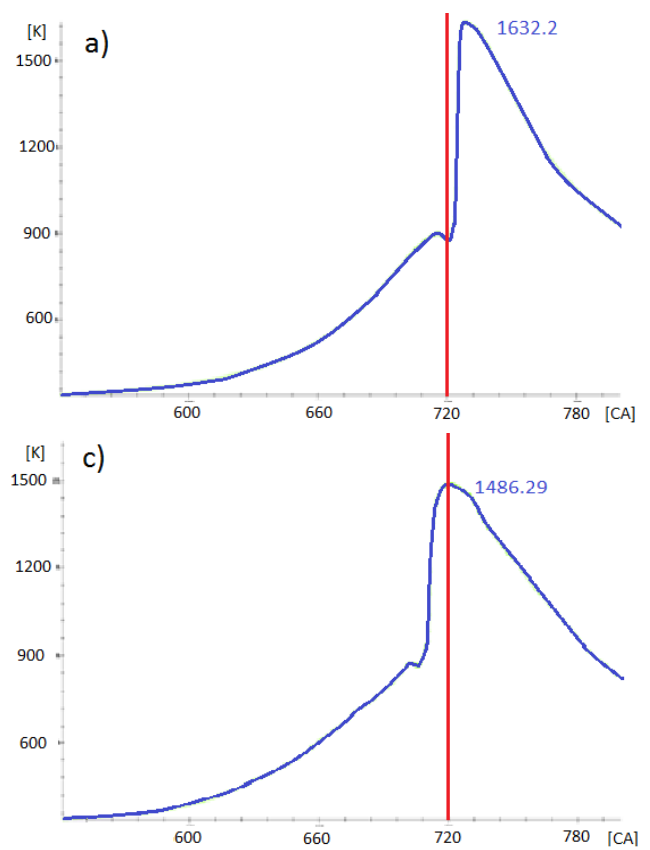

Fig. 9. Pressure distribution in engines: a) conventional, b) swingarm for TDC at $712-724^{\circ} \mathrm{CA}, \mathrm{c}$ ) swingarm for TDC at711-722 $\mathrm{CA}$, d) swingarm for TDC at710-730 $\mathrm{CA}$. The blue line marks $720^{\circ} \mathrm{CA}$

release process. At a later stage, a gentle drop in value contributes to the increase in the average temperature in the cylinders and facilitates the preparation of the next work cycle.

Simulation number two (Fig. 9b) was made for a swingarm engine while the piston remained in the TDC, for the range from 712 to $724^{\circ} \mathrm{CA}$. The maximum temperature of $1483.84 \mathrm{~K}$ was reached at the end of the TDC, i.e. $724^{\circ} \mathrm{CA}$. This means that the maximum temperature in the tested case is as much as $9 \%$ lower than for a conventional engine. The moment of the piston reaching the TDC is characterized by a slightly milder profile than for the first simulation. The unevenness of the pressure distribution decreased for this parameter. In the second stage, there is a steady, gentle temperature drop behind the TDC with a slight turbulence in the range of a few CA degrees from the start of the piston downwards motion, which was due to the combustion stroke extension.

Another analysis relied on engine control so that the piston remained in TDC in the range of $711-722^{\circ} \mathrm{CA}$ (Fig. 9c). The temperatures in this simulation showed violent changes near the TDC. A characteristic feature is the wide range for which high values of the parameter being kept above
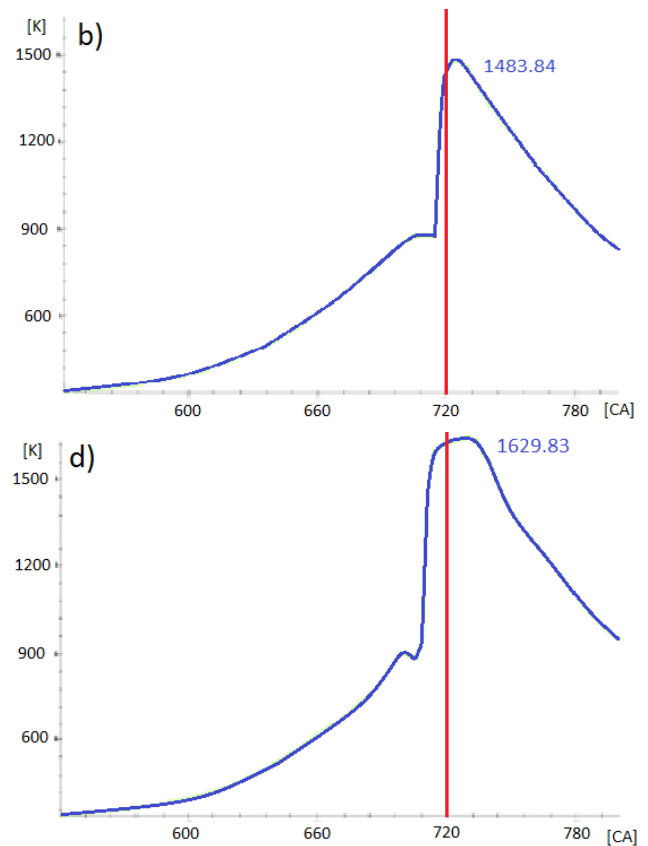
$1400 \mathrm{~K}$, compared to previous calculations. The maximum value was very similar to the previous simulation at $1486.29 \mathrm{~K}$ for $722^{\circ} \mathrm{CA}$.

The final analysis of the temperature curve is for the configuration of Szymkowiak's engine with a symmetrical displacement. The range of CA, for the piston in TDC, was $710-730^{\circ}$ (Fig. 9d). In this case, the curve reached the highest value among all the considered configurations aside from the conventional engine. The maximum temperature was $1629.83 \mathrm{~K}$. The maximum point was reached at $730^{\circ} \mathrm{CA}$. As the piston approaches the TDC the curve changes and a slight decrease in temperature occurs followed by a rapid jump of the parameter to the peak range above $1600 \mathrm{~K}$. There is a wide range where a constant temperature is maintained, which is the longest time period among all the tests. When the piston leaves the TDC, value of this parameter decreases.

\section{Heat Release Rate}

The heat release rate for the classic crank-piston system (Fig. 10a) was calculated by the software for a single injector hole, therefore the values presented should be multiplied by the number of injector holes, four in this case. This parameter should be understood as the amount of heat that is released in the 1st stage of crankshaft rotation. In a given simulation, the highest value obtained was $45.5 \mathrm{~J} /{ }^{\circ} \mathrm{CA}$. The heat release was the largest at $724.5^{\circ}$ CA. The beginning of the chemical combustion process in the chamber can be assumed to begin $1.5^{\circ} \mathrm{CA}$ after TDC $\left(720^{\circ} \mathrm{CA}\right)$, because a sharp increase in the parameter value can be seen. The top of the graph was a result of the high kinetic combustion process speed.

The CA range from 712 to $724^{\circ}$, in which the piston in the swingarm engine remains in the TDC (Fig. 10b) was then analyzed. The heat release rate from the chemical reaction began at $715^{\circ} \mathrm{CA}$. It can therefore be assumed that the ignition of the air/fuel mixture occurred $3^{\circ}$ after the TDC. The maximum value reached was $37.23 \mathrm{~J} /{ }^{\circ} \mathrm{CA}$. This result was lower by $8.27 \mathrm{~J} /{ }^{\circ} \mathrm{CA}$ than for the conventional crank-piston system test. This difference is significant for internal combustion engines as it amounts to 28 percent of the total value. The highest rate was observed at $716.25^{\circ} \mathrm{CA}$.

The next test was carried out for the programmed piston displacement with the piston remaining in the TDC in the range of $711^{\circ}$ to $722^{\circ}$ CA (Fig. 10c). The modeled displacement shows asymmetry from the conventional axis at $720^{\circ} \mathrm{CA}$, which results in significant piston acceleration during the compression stroke and extension of the combustion stroke. Heat release began at

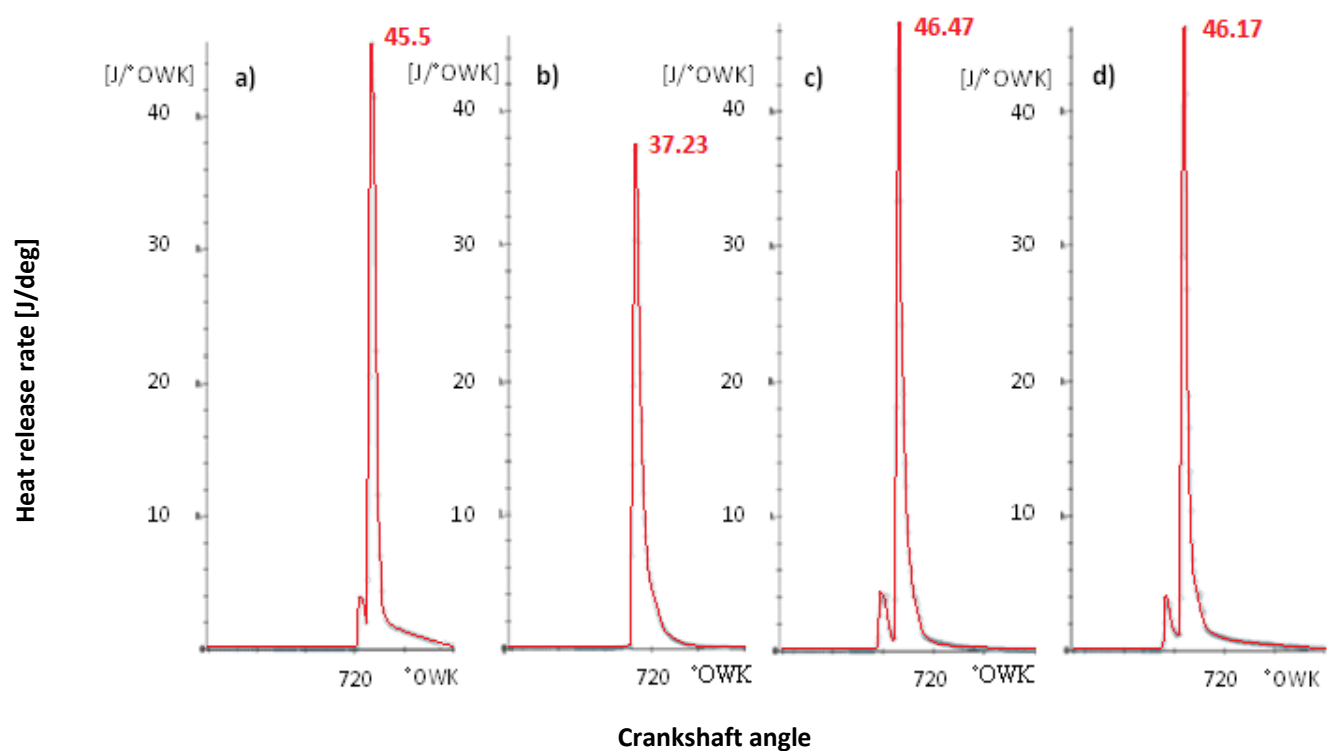

Fig. 10. The heat release rate in given engines: a) conventional, b) swingarm for TDC at $712-724^{\circ} \mathrm{CA}$,

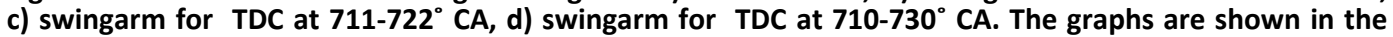
range $684-744^{\circ} \mathrm{CA}$ 
$711.25^{\circ} \mathrm{CA}$, that is $10.25^{\circ} \mathrm{CA}$ faster than in the case of a conventional engine. The graph shows sharp inflections in the low values CA range, possibly caused by the fuel-air mixture combustion. The parameter reached its maximum value a few degrees before the $720^{\circ} \mathrm{CA}$ mark, when passing $712^{\circ} \mathrm{CA}$, reaching $46.47 \mathrm{~J} / \mathrm{CA}$, which means the highest heat release rate among all simulations. Prior to the main heat release process, there are probably sudden local temperature increases of the evaporated fuel, which can also be seen.

In the final test, Szymkowiak's engine was controlled so that the piston remained in TDC in the range of $710-730^{\circ} \mathrm{CA}$ (Fig. 10d), making the period symmetrical about the $720^{\circ}$ point. The heat recovery rate, peaked at $710.5^{\circ} \mathrm{CA}$, due to kinetic combustion. In the end the maximum heat release rate value was $46.17 \mathrm{~J} /{ }^{\circ} \mathrm{CA}$. The process lasted a shorter time than in previous cases by $0.5^{\circ} \mathrm{CA}$, however, the duration of energy release in the low range below $5 \mathrm{~J} /{ }^{\circ} \mathrm{CA}$ was extended. Analyzing the curve presented in the figure and data calculated by the program, it can be assumed that the mixture ignition occurs for the crankshaft angle value equal to $710^{\circ}$, when the piston reaches TDC.

\section{Heat Losses}

The flux value $\dot{Q}$ of heat flow $Q$, that flows through surface $A$ in the normal (perpendicular) direction to this surface (1) and the heat flux density $q$ (2) for the described system are defined as shown below.

$$
\begin{gathered}
\dot{\mathrm{Q}}=\frac{\mathrm{dQ}}{\mathrm{dt}} \\
\mathrm{q}=\frac{\mathrm{d} \dot{\mathrm{Q}}}{\mathrm{dA}}
\end{gathered}
$$

The Fourier's law on the proportionality of the conducted heat density to the temperature gradient is shown in (3).

$$
q=-\lambda \frac{\partial T}{\partial n}
$$

where: $\lambda$-coefficient of heat transfer through the walls of the combustion chamber, $\mathrm{T}$-temperature of the medium transferring heat.

The amount of heat that will flow in the time interval $t$ through surface area $A$ is described by (4).

$$
Q=\oint_{A} \oint_{t} q \cdot d A \cdot d \tau
$$

Considering (3) and (4), it follows that the factors that affect the heat losses to the cooling system are: heat transfer coefficient, temperature gradient, surface area and heat exchange duration. The position and speed of the piston, therefore, plays a key role in the heat balance. Thus the piston displacement characteristic has an effect on heat losses to the cooling system.

In order to combine the results obtained from the two engines, the integration time t was limited to $720^{\circ} \mathrm{CA}$. Within this range, a full four-stroke engines work cycle is included. Assuming a constant engine speed of $2000 \mathrm{rpm}$, the heat exchange surface changes in the same way at each revolution of the crankshaft. The areas of the head and piston crown remain constant. The element whose surface area changes is the cylinder wall, which depends on the position of the piston at a given time. In this case, an approximation can be used for calculating this effect.

The variable surface value, which affects the instantaneous heat flux, can be noted as a constant $A_{z}$. Its value compensates for the effects of actual instantaneous values. Introduction of this constant makes it possible to exclude it from the integral, changing the double integral into single integral. While the angular parameter is expressed by (5).

$$
\alpha=\omega_{\mathrm{a}} \cdot \mathrm{t}
$$

where: $\omega_{\mathrm{a}}$ - the average value of angular velocity in time $\tau$

Hence the equation 6 is obtained

$$
\mathrm{d} \tau=\frac{1}{\omega_{\mathrm{a}}} \mathrm{d} \alpha
$$

A good solution for the asymmetrical piston displacement (case b and c) is the breakdown of (4) into four segments. The strokes need to be taken into account one after the other. In order to

$$
\mathrm{Q}=-\int_{0}^{720} \frac{\mathrm{A}_{\mathrm{z}}}{\omega_{\mathrm{a}}} \cdot \frac{\partial \mathrm{Q}}{\partial \mathrm{t}} \cdot \mathrm{dt}=-\mathrm{A}_{\mathrm{z}}\left[\int_{0}^{\alpha \mathrm{bc} 1} \frac{\lambda}{\omega_{\mathrm{a}}} \cdot \frac{\partial \mathrm{Q}}{\partial \mathrm{t}} \cdot \mathrm{d} \alpha+\int_{\alpha \mathrm{ae} 1}^{\alpha \mathrm{be} 1} \frac{\lambda}{\omega_{\mathrm{a}}} \cdot \frac{\partial \mathrm{Q}}{\partial \mathrm{t}} \cdot \mathrm{d} \alpha+\int_{\alpha \mathrm{ac} 2}^{\alpha \mathrm{bc} 2} \frac{\lambda}{\omega_{\mathrm{a}}} \cdot \frac{\partial \mathrm{Q}}{\partial \mathrm{t}} \cdot \mathrm{d} \alpha+\int_{\alpha \mathrm{ae} 2}^{720} \frac{\lambda}{\omega_{\mathrm{a}}} \cdot \frac{\partial \mathrm{Q}}{\partial \mathrm{t}} \cdot \mathrm{d} \alpha\right]
$$

where: $a$-beginning of the stroke, $b$-end of the stroke, $c$-compression, $e$-expansion, 1 - first crankshaft rotation, $2-$ second crankshaft rotation. 
simplify the notation, the sequence of strokes is: compression, combustion, compression, combustion, i.e. 2 full revolutions of the crankshaft - equation (7).

In the case of a symmetrical piston displacement (conventional engine and case d) equation (8) is true.

$$
\alpha_{\mathrm{bc}}-\alpha_{\mathrm{ac}}=\alpha_{\mathrm{be}}-\alpha_{\mathrm{ae}}
$$

The aforementioned relations at which heat losses occur in each types of strokes are mainly the heat transfer coefficient $\lambda$, the temperature gradient, and the surface $A_{z}$. For conventional engines, typical cylinder temperatures at the end of the compression stroke reach about 700-800 K. On the other hand, the maximum values resulting from the combustion reaction are several times greater than the values at the end of the compression stroke and are reached at the beginning of the combustion stroke. This phenomenon is presented in Figure 11. In this case, the temperature gradient has a dominant significance on the amount of heat lost. In the combustion stroke the gradient is much larger due to the much higher temperatures in the cylinder. This means that the amount of heat $Q_{e}$ released during the combustion stroke is significantly greater than the amount of heat $\mathrm{Q}_{c}$ lost during the compression stroke. The relation (9) is therefore significant.

$$
\mathrm{Q}_{\mathrm{e}}>\mathrm{Q}_{\mathrm{c}}
$$

For the asymmetric piston displacement, as for the swingarm engine in tests $b$ and $c$, condition (10) may be met.

$$
\alpha_{\mathrm{bc}}-\alpha_{\mathrm{ac}}<\alpha_{\mathrm{be}}-\alpha_{\mathrm{ae}}
$$

In the considered cases, when $\omega_{a}$ has a constant value, the combustion stroke is longer than the compression stroke, so the integration limits are not the same (7). After combining this fact with the temperature curve shown in Figure 11, the conclusion can be drawn. Assuming a constant engine load and a constant temperature of the cooling liquid, the temperature of the gases in the combustion chamber depends mainly on the position of the piston. In this situation, the value of the temperature derivative (3) depends on the location on the surface of the combustion chamber.

In the cases studied, the maximum temperature values differ from each other. The conventional engine has reached $1632.2 \mathrm{~K}$ which is the highest value of all simulations. Simulation of Szymkowiak's engine for the piston in TDC in the angular range of $710-730^{\circ} \mathrm{CA}$ yields a value close to that maximum, achieving a temperature of $1629.83 \mathrm{~K}$. This means that the differences between the two results are marginal. However, in the case of the Szymkowiak's engine test, the piston remains in TDC much longer than it does for the conventional engine. The result is a reduced combustion stroke duration. This affects the value of $A_{z}$, which in the case of the swingarm engine for a longer period of time is characterized by a smaller surface area. In this case, it means that thermal losses are greater in a conventional engine.

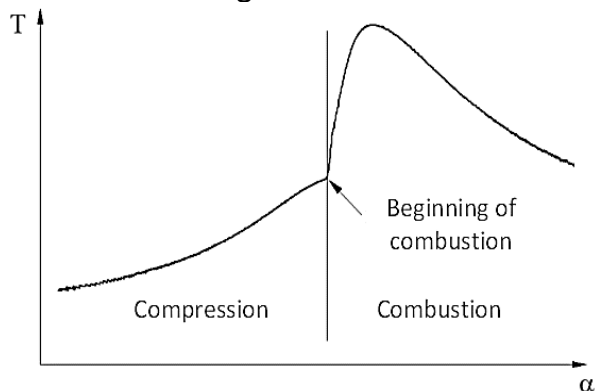

Fig. 11. Typical characteristic of temperature inside the cylinder

Considering the test for the swingarm engine with asymmetrical piston displacements, the maximum temperature values reached are very similar to each other. Subsequently, $1483.84 \mathrm{~K}$ and $1486.29 \mathrm{~K}$ for the piston in TDC in the range $712-724^{\circ}$ and $711-722^{\circ} \mathrm{CA}$. These values mean the difference for a conventional engine of up to $150 \mathrm{~K}$. This value has a significant influence on the temperature gradient and consequently on heat losses where the conventional engine is at a disadvantage. In a swingarm engine, the maximum temperature values are reached in the CA range while the piston is in TDC. In contrast to the conventional engine, where the main combustion takes place after TDC and therefore during the combustion stroke, when the piston is already in motion. In addition, the combustion stroke in Szymkowiak's engine takes less time for both configurations. These phenomena impact the $A_{z}$ value to a significant degree. The instantaneous surface area of the combustion chamber walls in the swingarm engine for a longer period of time is characterized by smaller values. This translates into a smaller area through which the heat from the combustion reaction can transfer out of the system. Which means higher thermal efficiency of the Szymkowiak's engine.

With the above configurations, it is possible to impact the engine thermal efficiency and, hence also the overall efficiency of the internal combustion engine. 


\section{CONCLUSIONS}

The simulation analysis of thermal processes in the VCR engine were performed to show the impact of the piston displacement and the duration of the piston remaining in the Top Dead Center on the engine parameters of Szymkowiak's engine. Thanks to using computer simulation in specialized AVL Fire software, the simulation process was relatively quick and enabled the measurement of more parameters than a measurement performed on a real engine.

Due to the complexity of the swingarm mechanism, the mechanical efficiency may be slightly lower compared to a conventional unit. However asymmetry of the piston movement in Szymkowiak's engine affects the duration of the compression and combustion strokes and can be used to reduce heat losses to the cooling system. The comparison of the mean cylinder pressure and indicated work of one engine cycle indicates (increase of the maximum pressure in the cylinder by approx. 6\%) that the use of the mechanism for changing the compression ratio in the described structure can be expected to increase the engine torque, which is advantageous from the point of view of engine dynamics, and increase in indicated work. The result of the simulation of thermodynamic indicators for specific values of structural parameters indicates that the overall engine efficiency can also be expected to increase. Thanks to the modified structure of the Szymkowiak's engine, it is possible to continuously adjust the compression ratio in the entire range of engine operation, similar to the adjustment of, for example, the fuel injection timing. Thanks to this, it becomes possible to adjust the ignition timing and expand the working area of the engine in which $\mathrm{HCCl}$ type combustion can be achieved.

The simulations were performed without prior optimization of parameters such as, for example: fuel injection strategy, injector type, fuel injection time, piston crown shape, ignition timing and others.

\section{ABBREVIATIONS}

1. Clengine-Compression Ignition engine

2. TDC-Top Dead Center of the piston;

3. Solidworks Motion - Solidworks module that allows to create simulations and analyzes of moving and interacting objects;

4. VCR-Variable Compression Ratio;

5. BDC-Bottom Dead Center of the piston;

6. ESE Diesel - Engine Simulation Environment - AVL Fire module, which allows to simulate, analyze and optimize aerodynamics, fuel injection, combustion and emission formation in Diesel engine;

7. CA-Crankshaft Angle;

8. ECFM-3Z-Extended CoherentFlame Model-3Zones-combustion model that can be used for both gasoline and diesel auto-ignition applications. This is the recommended choice by AVL producer.

\section{WPtYW STEROWANIA WAtKIEM ROZRZĄDU NA PROCESY SPALANIA W SILNIKU VCR Z ZAPŁONEM SAMOCZYNNYM}

Artykuł zawiera analizę wskaźników termodynamicznych procesu spalania silnika Cl z bezpośrednim wtryskiem paliwa. Badaną jednostką był silnik o niekonwencjonalnym układzie korbowo-tłokowym, w którym przy stałym stopniu sprężania poprzez wysterowanie krzywki w silniku porównano różne warianty jej ustawienia. W niniejszym artykule poddane analizie zostały zakresy czasowe w jakich tłok znajdował się w Górnym Martwym Punkcie (GMP). Dodatkowo w celach porównawczych przeprowadzono badania na jednostce konwencjonalnej. Na potrzeby pracy wygenerowana została droga tłoka w analizie dynamicznej w programie Solidworks Motion. Następnie charakterystyka ta została wykorzystana w symulacjach procesu spalania w programie AVL Fire, gdzie analizie zostały poddane najważniejsze wskaźniki termodynamiczne obiegu silnikowego.

Słowa kluczowe: Silnik VCR, indykowanie, AVL Fire

\section{BIBLIOGRAPHY}

[1] Heywood J. (2018) Internal Combustion Engine Fundamentals. McGraw-Hill Education

[2] Freudenstein F, Maki ER. (1983) „Development of an optimum variable-stroke internal combustion engine mechanism from the viewpoint of kinematic structure", Journal of Mechanisms Transmissions and Automation in Design, 105, pp. 259-266

[3] Hoeltgebaum T, Simoni R, Martins D. (2016) „Reconfigurability of engines: A kinematic approach to variable compression ratio engines", Mechanism and Machine Theory, 96, pp. 308322, doi.org/10.1016/j.mechmachtheory.2015.10.003

[4] Mahesh PJ, Aparna VK. (2012) „Variable compression ratio engine - A review of future power plant for automobile", International Journal of Mechanical Engineering Research and Development (IJMERD), ISSN 2228-9355, (2)1, pp. 9-16

[5] Shaik A, Shenbaga N, Moorthi V, Rudramoorthy R. (2007) Variable compression ratio engine: A future power plant for automobiles - an overview, doi.org/10.1243/09544070JAUTO573

[6] Yamin JAA, Dado MH. (2004) "Performance simulation of a four-stroke engine with variable stroke-length and compression ratio", Applied Energy, 77(4), pp.447-463

[7] Rychter T, Teodorczyk A. (1995) "Variable Compression Ratio Engine - Vr/Le Concept". Journal of Power Technologies, 79

[8] Nagarajaa S, Sooryaprakashb K, Sudhakaran R. (2015) "Investigate the Effect of Compression Ratio over the Performance and Emission Characteristics of Variable Compression Ratio Engine Fueled with Preheated Palm Oil -Diesel Blends", Procedia Earth and Planetary Science doi.org/10.1016/j.proeps.2015.06.038

[9] Eriksson L, Nielsen I. (2014) Modeling and control of engines and drivelines (London: John Wiley \& Sons)

[10] Rymaniak L. (2017) „Comparison of the combustion engine operating parameters and the ecological indicators of an urban bus in dynamic type approval tests and in actual operating conditions". In: MATEC Web of Conferences. EDP Sciences, p. 00009.

[11] Sivaramakrishnan K.(2017) „Investigation on performance and emission characteristics of a variable compression multi fuel engine fuelled with Karanja biodiesel-diesel blend", Egyptian Journal of Petroleum, doi.org/10.1016/j.ejpe.2017.03.001 